\title{
APLIKASI KAMUS BAHASA HELONG BERBASIS ANDROID
}

\author{
Roland Koen \\ Teknik Informatika, STIKOM Uyelindo, rolandkoen5@ gmail.com \\ Semlinda Juszandri Bulan \\ Sistem Informasi, STIKOM Uyelindo, semlinda@yahoo.com
}

\begin{abstract}
Abstrak
Kamus merupakan sebuah rujukan untuk mencari makna atau arti dari kata-kata. Kamus memiliki berbagai macam bentuk tetapi bentuk yang lebih banyak digunakan pada saat ini adalah kamus berbentuk aplikasi pada smartphone karena keunggulannya yang lebih fleksibel. Penelitian ini bertujuan untuk membuat aplikasi kamus bahasa Helong yang diterjemahkan ke bahasa Indonesia dan bahasa Inggris yang dapat digunakan pada smarthphone berbasis Android. Bahasa Helong merupakan salah satu bahasa dari antara ribuan bahasa daerah di Indonesia. Sebagai bahasa daerah, bahasa Helong memiliki ciri khas dalam hal tata bahasa dan arti kata sehingga hal itu yang membedakannya dari bahasa lain. Karena masyarakat suku Helong hidup berdampingan dengan masyarakat multisuku maka fenomena pergeseran bahasa dapat saja terjadi dan juga pulau Semau yang merupakan bermukimnya masyarakat suku Helong sering dikunjungi oleh wisatawan sehingga dalam hal ini bahasa Helong perlu untuk dilestarikan. Aplikasi kamus Bahasa Helong ini dapat membantu melestarikan bahasa Helong untuk masyarakat suku Helong maupun kepada wisatawan. Dalam Aplikasi ini pengguna dapat menemukan terjemahan dalam bahasa Helong, bahasa Indonesia maupun bahasa Inggris secara efektif dan efisien dan juga dapat mengetahui cara pengucapannya karena dalam aplikasi ini sudah dilengkapi dengan audio. Data yang digunakan dalam penelitian ini diperoleh dari buku referensi dan literatur serta data berupa kosakata bahasa Helong yang diperoleh melalui wawancara. Dengan adanya Aplikasi kamus bahasa Helong ini maka dapat melestarikan bahasa Helong kepada masyarakat suku Helong serta lebih memudahkan dalam memperkenalkan bahasa Helong kepada wisatawan lokal maupun wisatawan mancanegara.
\end{abstract}

Kata Kunci: android, bahasa helong, kamus, smartphone

\section{PENDAHULUAN}

Seiring dengan berkembangnya teknologi informasi menyebabkan semakin banyak orang mengerti akan pentingnya fungsi komputer dalam membantu pekerjaan yang dikerjakan. Saat ini perkembangan komputer telah membawa perubahan besar dalam berbagai bidang. Perkembangan teknologi informasi, selain perkembangan aplikasi desktop pada komputer juga meliputi perkembangan aplikasi mobile. Seperti yang diketahui saat ini, kebutuhan manusia tidak pernah terbatas seperti kebutuhan komunikasi sehingga handphone yang dikenal sebagai alat komunikasi genggam semakin berkembang pesat dengan aplikasi-aplikasi terbaru dan bermanfaat untuk kebutuhan manusia. Semakin berkembang aplikasi mobile maka terciptalah sebuah sistem operasi yang dikembangkan untuk perangkat mobile berbasis Linux yaitu Android yang merupakan pilihan yang tepat untuk pengembang.

Bahasa Helong adalah bahasa pertama yang digunakan suku Helong yang bermukim di wilayah ujung barat pulau Timor dekat pelabuhan Tenau, Kota Kupang hingga wilayah Amarasi, dan sebagian besar desa di pulau Semau. Bahasa Helong termasuk salah satu rumpun bahasa Austronesia di Indonesia Timur, khususnya di wilayah Nusa Tenggara Timur. Sistem kekerabatan Suku Helong yang terkecil adalah keluarga inti, yang bergabung menjadi keluarga luas terbatas (ngalo). Beberapa ngalo bergabung membentuk klan (ingu) yang dipimpin seorang pemimpin klan (koka ana) seketurunan tersebut. Dalam hal strata sosial, masyarakat Helong zaman dahulu terbagi menjadi tiga lapisan, yaitu bangsawan (usif), orang kebanyakan (tob), dan hamba sahaya (ata). 
Mengingat masyarakat suku Helong hidup berdampingan dengan masyarakat multisuku yang mempertahankan identitas kesukuannya masingmasing, maka fenomena pergeseran bahasa dan kepunahan bahasa dapat saja terjadi. Hal yang dapat menyebabkan terjadinya pergeseran bahasa adalah jika masyarakat pemakai Bahasa Helong memilih bahasa baru untuk mengganti bahasa sebelumnya. Dengan kata lain, pergeseran bahasa terjadi karena masyarakat suku Helong beralih ke bahasa lain yang dominan dan berprestise, yang digunakan dalam ranah-ranah pemakaian bahasa yang lama. Seiring berjalannya waktu minat seseorang terhadap Bahasa Helong kini sudah mulai menurun khususnya kaum muda, sehingga ketika berbicara kepada orang yang lebih tua cenderung tidak memakai Bahasa Helong dengan baik dan benar. Sekalipun berbicara dengan Bahasa Helong itupun tidak berbicara Bahasa Helong dengan benar, melainkan dipadukan atau dicampur dengan Bahasa Indonesia sehingga kini Bahasa Helong perlu untuk diperkuat lagi agar masyarakat suku Helong dapat berbahasa Helong dengan baik.

Selain untuk menjaga pelestarian Bahasa Helong, saat ini Pulau Semau yang menjadi destinasi wisata baik itu pantai dan tempat lainnya yang diminati oleh para wisatawan yang sering berkunjung ke Pulau Semau. Maka dari itu komunikasi menjadi salah satu kendala bagi wisatawan untuk berkomunikasi dengan masyarakat di pulau Semau yang mayoritas masih berkomunikasi dengan Bahasa Helong.

Sejalan dengan berkembangnya teknologi yang ada sekarang ini, kita dituntut pula untuk bisa beradaptasi dengan perkembangan tersebut, sehingga sumber daya manusianya (SDM) harus berkembang pula. Penyelarasan dengan perkembangan teknologi menuntut masyarakat untuk bisa mengetahui dan memahami bahasa-bahasa yang ada di dunia, baik dalam maupun luar negeri. Salah satu bahasa yang ada dalam negeri yaitu bahasa Helong.

Pada penelitian ini penulis membuat Aplikasi Kamus Bahasa Helong yang diterjemahkan ke dalam bahasa Indonesia dan bahasa Inggris yang dilengkapi dengan audio agar pengguna dapat menerjemahkan kata maupun dapat mengetahui tentang pengucapan kata tersebut. Kamus ini dapat dipakai menggunakan Handphone berbasis Android agar bisa membantu bagi pelestarian Bahasa Helong kepada masayarakat suku Helong yang ingin mengetahui dan belajar Bahasa Helong maupun kepada wisatawan lokal dan wisatawan mancanegara agar dapat berkomunikasi dengan masyarakat Pulau Semau menggunakan Bahasa Helong ketika berkunjung ke Pulau Semau.

\section{TINJAUAN PUSTAKA}

\subsection{Helong}

Menurut [1], Helong atau Halong adalah sebuah suku yang mendiami pulau Semau atau pulau Timau. Suku Helong berasal dari Pulau Ambon. Helong sebenarnya berasal dari kata Halong, yang oleh orang yang tinggal di sana susah untuk menyebutkan kata Halong dan lebih senang menyebutkannya menjadi Helong. Helong atau Halong adalah sebuah pulau di Ambon (Maluku) tempat di mana Suku Helong Berasal. Suku Helong sebenarnya dari Nusa Ina, nama lain dari Pulau Seram. Seram merupakan pulau yang berada pada gugusan kepulauan Maluku. Pulau Seram luasnya $18.625 \mathrm{~km}^{2}$ dengan panjang $340 \mathrm{~km}$ dan lebar $60 \mathrm{~km}$. Pulau ini digambarkan memiliki alam yang subur, dengan hutan tropis. Puncak tertinggi di sana bernama Gunung Binaiya. Awalnya etnis Helong berdiam di Pulau Seram. Namun entah apa alasannya, suku ini bermigrasi ke Pulau Timor. Dugaan sementara, migrasi karena bencana alam atau karena konflik saudara. Namun hipotesa ini perlu diuji lebih lanjut. Secara asal usul kata, Helong berasal dari kata he yang berarti jual dan lo berarti tidak. Kata helo berarti tidak dijual. Secara umum, kata helo berarti pengorbanan atau rela berkorban. Filosofi etnis Helong diyakini mewarisi sikap sedia berkorban dan tidak rela kalau lingkungannya diganggu. Jika diganggu, maka dia berbalik membalas. ketika orang menunjuk ke Pulau Semau-yang acapkali disebut Bung Tilu (tiga kembang) - terungkap makna, "Semau tidak dijual."

\subsection{Kamus}

Menurut [2], kamus adalah buku acuan yang didalamnya memuat kata yang disusun menurut abjad berikut keterangan tentang maknanya, pemakaiannya dan terjemahannya. Kamus juga merupakan buku rujukan yang membantu seseorang untuk mengenal dan memahami perkataan baru. Kamus juga digunakan sebagai pedoman bagaimana suatu kata digunakan. Terdapat banyak jenis-jenis kamus, antara lain kamus berdasarkan penggunaan bahasa, berdasarkan isi, dan berdasarkan bentuk medianya.

\subsection{Android}

Menurut [3], Android adalah sebuah kumpulan perangkat lunak untuk perangkat mobile yang mencakup sistem operasi, middleware dan aplikasi utama mobile. Sedangkan menurut [4], Android 
merupakan OS (Operating System) Mobile yang berkembang diantara OS lainnya seperti Windows Mobile, IOS (Apple), Symbian, dan masih banyak lagi.

Adapun beberapa fitur-fitur yang tersedia di Android adalah sebagai berikut (Safaat, 2012):

a) Kerangka aplikasi memungkinkan penggunaan dan penghapusan komponen yang tersedia.

b) Dalvik mesin virtual yaitu mesin virtual dioptimalkan untuk perangkat telepon seluler.

c) Grafik yaitu grafik di 2D dan grafis 3D berdasarkan pustaka OpenGL.

d) SQLite untuk menyimpan data.

e) Mendukung media: audio, video dan berbagai format gambar (MPEG4, H.264, MP3, AAC, AMR, JPG, PNG, GIF).

f) GSM, Bluetooth, EDGE, 3G, 4G, dan wifi (tergantung piranti keras).

g) Kamera, Global positioning system (GPS), Kompas, NFC danaccelerometer (tergantung piranti keras).

\subsection{Penelitian Terdahulu}

[5] membuat Aplikasi Translator Bahasa Jawa ke Bahasa Indonesia Berbasis Android. Penelitian ini bertujuan untuk merancang aplikasi translator digital Jawa-Indonesia dan Indonesia-Jawa untuk perangkat mobile khususnya smartphone yang berbasis Android, pengguna sistem dapat menerjemahkan bahasa Jawa ke dalam bahasa Indonesia dan sebaliknya kapan saja dan dimana saja. Metode yang digunakan dalam pembuatan aplikasi ini adalah brute force dan binary search.

[6] mengembangkan Smart Application Translation Aneka Bahasa Sulawesi berbasis Android. Untuk mengembangkan aplikasi ini digunakan Linear Sequential Model, untuk memudahkan proses pengembangan. Setelah melalui tahap pengembangan maka aplikasi ini telah berjalan dengan baik melalui proses pengujian sehingga aplikasi Translator Indonesia-Sulawesi ini sudah dapat diakses melalui Google Play Store.

\section{METODE}

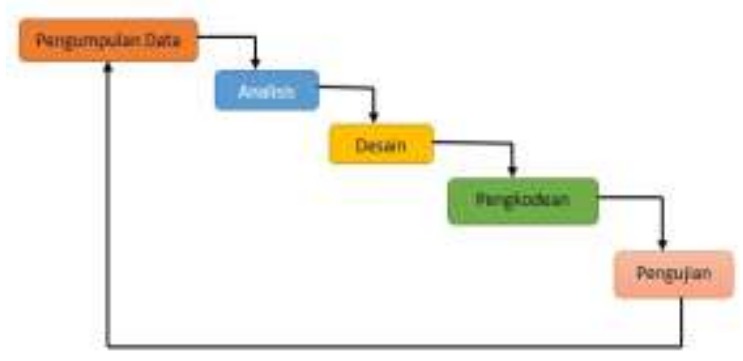

Gambar 1. System Development Life Cycle

\section{Pengumpulan Data}

Penulis mencari studi literatur berupa jurnal dan buku-buku serta referensi hasil penelitian sebelumnya yang didapat melalui internet maupun perpustakaan, yang berkaitan dengan penelitan kemudian melakukan observasi terhadap tempat penelitian lalu melakukan wawancara untuk mendapatkan data berupa kosakata Bahasa Helong dari tokoh adat Suku Helong yang diwawancarai.

\section{Analisa kebutuhan perangkat lunak}

Analisa kebutuhan adalah suatu proses untuk mendapatkan informasi, mode, spesifikasi tentang perangkat lunak yang diinginkan pengguna. Kedua belah pihak, yaitu pengguna dan pembuat perangkat lunak terlibat aktif dalam tahap ini. Informasi dari pengguna yang akan menjadi acuan untuk melakukan desain perangkat lunak.

Analisis kebutuhan merupakan satu di antara banyak aktivitas kritis pada proses rekayasa kebutuhan perangkat lunak untuk memahami ranah permasalahan dari sistem yang berjalan dan ranah solusi dari sistem yang akan dibuat. Ada tiga faktor yang harus dipenuhi ketika melakukan analisis kebutuhan ini, yaitu 
lengkap, detail, dan benar. Lengkap artinya semua yang diharapkan oleh pengguna telah didapatkan oleh pihak yang melakukan analisis. Detail maksudnya adalah berhasil mengumpulkan informasi yang terperinci. Semua data dari analisis kebutuhan ini haruslah benar, sesuai apa yang dimaksud oleh pengguna, bukan benar menurut apa yang dipikirkan oleh pihak analisis. Analisis kebutuhan yang dilakukan terhadap perangkat lunak akan menghasilkan spesifikasi perangkat lunak tersebut. Analisa kebutuhan ini terdiri dari lima langkah:

a. Identifikasi masalah

b. Evaluasi dan sintesis

c. Pemodelan

d. Spesifikasi

e. Review

\section{Desain perangkat lunak}

Desain perangkat lunak bukan hanya sebuah perancangan berupa interface (antarmuka) sebuah perangkat lunak, tetapi memiliki lingkup yang jauh lebih luas. Sebuah proses untuk mendefinisikan sesuatu yang akan dikerjakan dengan menggunakan teknik yang bervariasi serta didalamnya melibatkan deskripsi mengenai arsitektur serta detail komponen dan juga keterbatasan yang akan dialami dalam proses pengerjaannya.

Sebuah proses perancangan membutuhkan pengetahuan mengenai berbagai teknik atau model perancangan yang dapat digunakan. Selain itu, sebuah perancangan membutuhkan hasil analisa yang telah mampu mendeskripsikan kebutuhan dari sistem yang akan dibuat dan seorang desainer harus memahami kendala atau hambatan yang mungkin terjadi pada saat implementasi.

Ini berarti bahwa sebuah proses perancangan memiliki 3 unsur penting, yakni:

a. Pengetahuan mengenai teknik perancangan.

b. Kebutuhan sistem.

c. Kendala yang mungkin terjadi.

Desain Perangkat Lunak merupakan sebuah proses yang berkelanjutan dari analisa dan didalamnya melakukan identifikasi hasil analisa serta menghasilkan konsep dasar untuk kepentingan pengembangan perangkat lunak. Dalam pengertian yang sama, dapat digolongkan bahwa perancangan adalah mengubah dari "apa" yang menjadi kebutuhan, menjadi "bagaimana" mendefinisikan kebutuhan tersebut menjadi sebuah perangkat lunak.

\section{Pengkodean Perangkat lunak}

Pada tahap ini penulis menggunakan Eclipse untuk membuat Aplikasi Kamus Bahasa Helong Berbasis Android.

Android adalah salah satu sistem operasi mobile yang bersifat Open Source, yang dimana source code dari sistemnya terbuka, dan dapat dikembangkan oleh siapa saja. Berbasiskan software Linux yang dibangun untuk berbagai jenis bentuk perangkat dan platform. Terdapat beberapa komponen utama yang berjalan saat menggunakan perangkat yang menggunakan OS Android. Komponen utamanya seperti : System Apps, Java API Framework, Linux Kernel dan lain-lain. Java JDK adalah sebuah perangkat lunak yang digunakan untuk melakukan proses kompilasi dari kode Java ke bytecode yang dapat dimengerti dan dapat dijalankan oleh JRE (Java Runtime Envirotment).

\section{Pengujian perangkat lunak}

Pada tahap pengujian bertujuan untuk memastikan apakah perangkat lunak yang dibangun dapat berjalan dengan baik. Dapat dikatakan bahwa tujuan utama pengujian perangkat lunak adalah untuk memastikan tidak ada kesalahan dan sesuai dengan ekspektasi yang diharapkan yang tertuang dalam rencana dan perancangan yang telah dibuat dan disetujui sebelumnya.

\subsection{Perancangan}

Tahapan perancangan yang meliputi: use case diagram, arsitektur layar dan class diagram.

\section{Use Case Diagram}

Use case diagram adalah gambaran graphical dari beberapa atau semua actor, use case, dan interaksi di antara komponen-komponen tersebut yang memperkenalkan suatu sistem yang akan dibangun digunakan untuk menjelaskan bagaimana langkahlangkah yang seharusnya dikerjakan oleh sistem. Use case diagram menjelaskan manfaat suatu sistem jika dilihat menurut pandangan orang yang berada di luar sistem. Diagram ini menunjukkan fungsionalitas suatu sistem atau kelas dan bagaimana sistem tersebut berinteraksi dengan dunia luar. Adapaun use case pada aplikasi kamus bahasa Helong adalah sebagai berikut: 


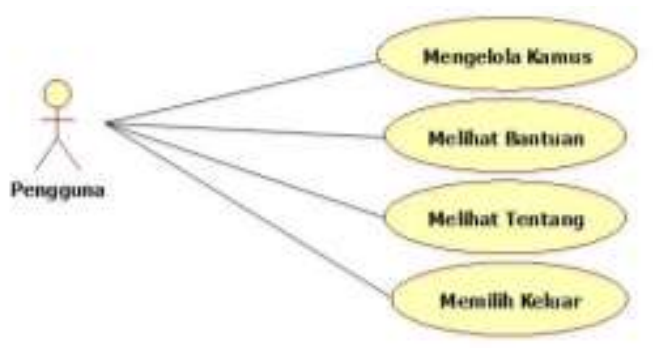

Gambar 2. Use case diagram

1. Arsitektur layar

Perancangan arsitektur layar berfungsi untuk mendeskripsikan kategori sistem sebagai penghubung antar komponen dan user interface. Perancangan arsitektur yang digunakan adalah arsitektur layar (layer architecture) di mana terdapat pemisahan tanggung jawab dari setiap layar. Perancangan arsitektur layar aplikasi ini dapat dilihat pada Gambar 3 berikut:

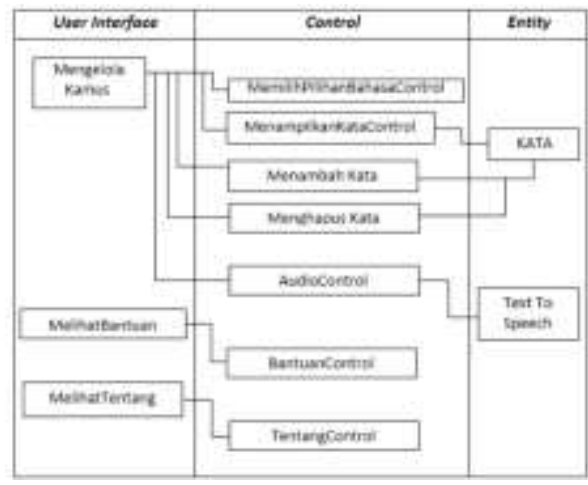

Gambar 3. Arsitektur layar

\section{Class Diagram}

Class diagram merupakan suatu diagram yang memperlihatkan atau menampilkan struktur dari sebuah sistem. Sistem tersebut akan menampilkan sistem kelas, atribut dan hubungan antar kelas ketika suatu sistem telah selesai membuat diagram. Perancangan class diagram aplikasi selengkapnya dapat dilihat pada Gambar 4 berikut:
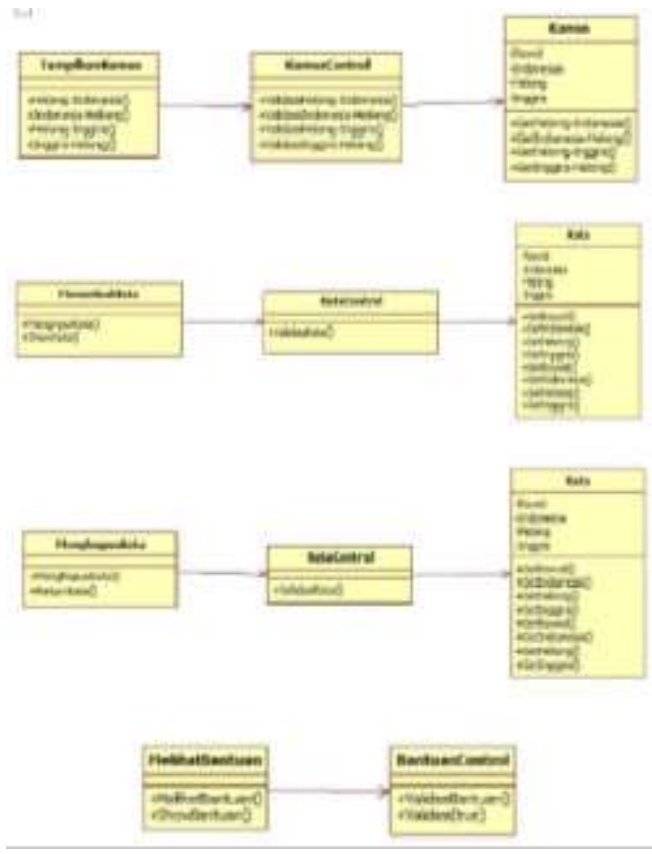

Gambar 4. Class diagram

Gambar 4 merupakan Class diagram dari aplikasi kamus bahasa Helong yang digunakan oleh pengguna untuk menampilkan, menambah serta menghapus kata dan juga untuk melihat menu-menu aplikasi pada smartphone.

\section{HASIL DAN PEMBAHASAN}

Aplikasi kamus bahasa Helong berbasis Android merupakan aplikasi kamus yang dapat menerjemahkan bahasa Helong ke bahasa Indonesia maupun bahasa Helong ke bahasa Inggris dan sebaliknya. Dalam apliaksi ini juga dilengkapi dengan audio sehingga dapat memudahkan pengguna untuk mengetahui cara pengucapan. Aplikasi ini dapat digunakan oleh masyarakat suku Helong maupun wisatawan sehingga dapat melestarikan bahasa Helong.

\section{Antarmuka menu utama}

Antarmuka menu utama aplikasi kamus bahasa Helong berfungsi menampilkan tombol pilihan yang dapat digunakan pengguna untuk menggunakan aplikasi. 


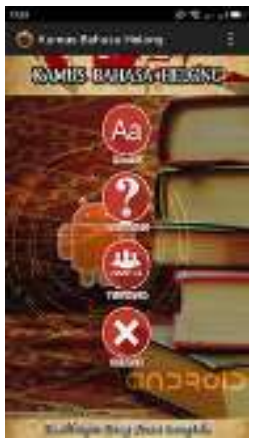

Gambar 5. Antarmuka menu utama

\section{Antarmuka Kamus}

Antarmuka kamus digunakan pengguna untuk memilih pilihan bahasa yang sudah tersedia sebelum menampilkant kata yang ingin diterjemahkan. Ada 4 pilihan yaitu Helong - Indonesia, Indonesia - Helong, Helong - Inggris, Inggris - Helong.

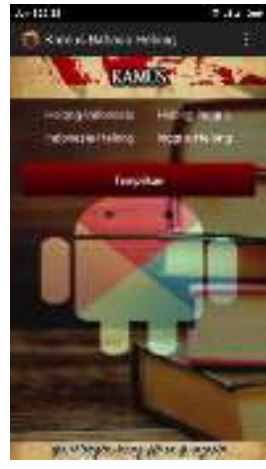

Gambar 6. Antarmuka kamus

\section{Antarmuka Tambah Kata}

Antarmuka tambah kata digunakan pengguna untuk menambah kata pada aplikasi

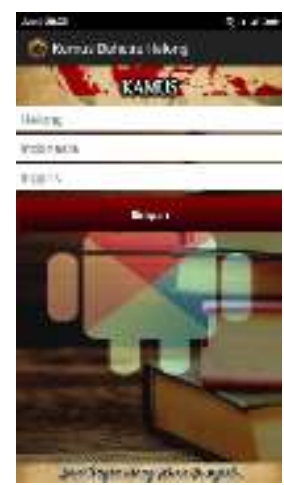

\section{Gambar 7. Antarmuka tambah kata}

\section{Antarmuka Hapus Kata}

Antarmuka hapus kata digunakan pengguna untuk menghapus kata pada aplikasi.

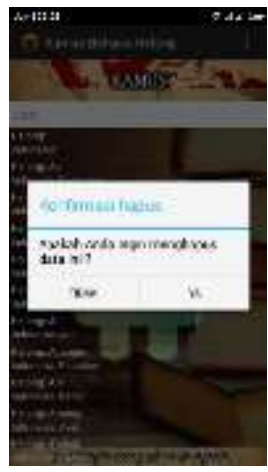

\section{Gambar 8. Antarmuka hapus kata}

\section{Antarmuka Bantuan}

Antarmuka bantuan digunakan pengguna untuk melihat cara penggunaan aplikasi yang menjelaskan tentang tombol-tombol yang tersedia dalam aplikasi.

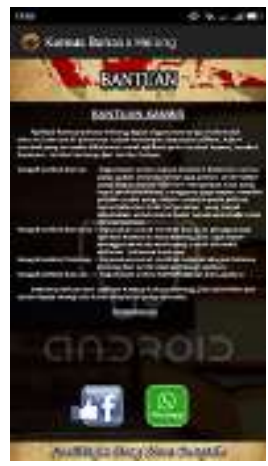

Gambar 9. Antarmuka bantuan

\section{KESIMPULAN}

Aplikasi kamus bahasa Helong adalah aplikasi kamus bahasa daerah yang menerjemahkan bahasa Helong ke bahasa Indonesia dan sebaliknya serta bahasa Helong ke bahasa Inggris dan sebaliknya. Aplikasi ini melakukan dapat menerjemahkan kata maupun audio. Dengan adanya aplikasi ini lebih 
memudahkan dalam melestarikan bahasa Helong kepada masyarakat suku Helong serta dapat memperkenalkan bahasa Helong kepada wisatawan lokal maupun wisatawan mancanegara.

\section{DAFTAR PUSTAKA}

[1] Luitnan, I.A. 2012. Koepang Tempo Doeloe. Ruas. Depok.

[2] Hoetomo, M.A. 2005. Kamus Lengkap Bahasa Indonesia. Mitra Pelajar Surabaya.

[3] Safaat, N. 2012. Pemrograman Aplikasi Mobile Smartphone dan Tablet PC Berbasis Android. Informatika. Bandung.

[4] Hermawan, S. 2011. Mudah membuat Aplikasi Android. Andi Offset. Yogyakarta.

[5] Setiawan, A.B., Buana, P.W. dan Sukarsa, I.M. 2014. Aplikasi Translator Bahasa Jawa ke Bahasa Indonesia Berbasis Android. Merpati. Vol. 2. No. 3. Hal. 344-350.

[6] Maslan, A., Setiono, Y., dan Alfazri, F. 2016. Pengembangan Smart Application Translation Aneka Bahasa Sulawesi berbasis Android. Teknosi, Vol. 02. No. 01. Hal. 55-64.

[7] Turban, E. 2003. Introduction of Information Technology, 2nd Edition John Wiley \& Sons. Inc. New York. US 